University of Baghdad

College of Engineering

(1)

JOURNAL OF ENGINEERINC
Journal of Engineering

journal homepage: www.joe.uobaghdad.edu.iq

Number 4 Volume 26 April 2020

Civil and Architectural Engineering

\title{
Experimental and Numerical Study on CFRP-Confined Square Concrete Compression Members Subjected to Compressive Loading
}

\author{
Ahmed W. Abdulsattar* \\ M.Sc. student, Department of Civil Engineering, \\ College of Engineering, University of Baghdad \\ Baghdad, Iraq. \\ Ahmad_Waad_24@yahoo.com
}

\author{
Dr. Hayder A. Al-Baghdadi \\ Faculty Member, Department of Civil Engineering, \\ College of Engineering University of Baghdad \\ Baghdad, Iraq, \\ baghdadi.hayder@coeng.uobaghdad.edu.iq
}

\begin{abstract}
Strengthening of the existing structures is an important task that civil engineers continuously face. Compression members, especially columns, being the most important members of any structure, are the most important members to strengthen if the need ever arise. The method of strengthening compression members by direct wrapping by Carbon Fiber Reinforced Polymer (CFRP) was adopted in this research. Since the concrete material is a heterogeneous and complex in behavior, thus, the behavior of the confined compression members subjected to uniaxial stress is investigated by finite element (FE) models created using Abaqus CAE 2017 software.

The aim of this research is to study experimentally and numerically, the behavior of square plain (without steel reinforcement) concrete compression members, that has concrete strength of $\mathrm{f}_{\mathrm{c}}^{\prime}=$ 24.41 MPa, confined with one layer of CFRP wraps under uniaxial compressive loading. Finally, the outcomes are compared with the finite element models using Abaqus software.

Laboratory experimental results showed that confining compression members with CFRP wraps is an efficient strengthening method. In terms of load carrying capacity, an enhancement was measured for about $56.1 \%$ of the reference non-confined members. This enhancement was also reached using Abaqus software.
\end{abstract}

Key words: Finite element, Concrete Damaged Plasticity Model (CDPM), CFRP sheets, Compression members, Confinement.

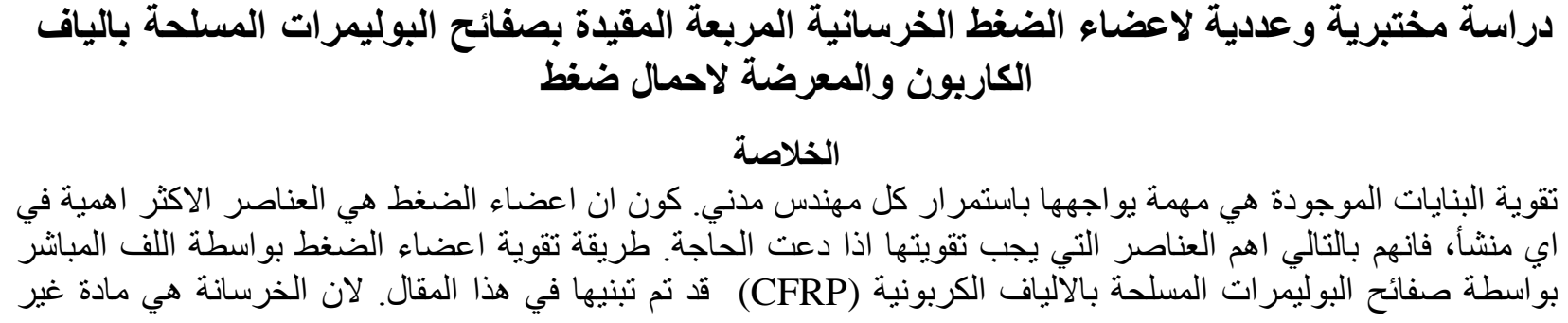

*Corresponding author

Peer review under the responsibility of University of Baghdad.

https://doi.org/10.31026/j.eng.2020.04.10

2520-3339 (C) 2019 University of Baghdad. Production and hosting by Journal of Engineering.

This is an open access article under the CC BY4 license http://creativecommons.org/licenses/by /4.0/).

Article received: $30 / 6 / 2019$

Article accepted:7 /12/2019

Article published:1/4/2020 


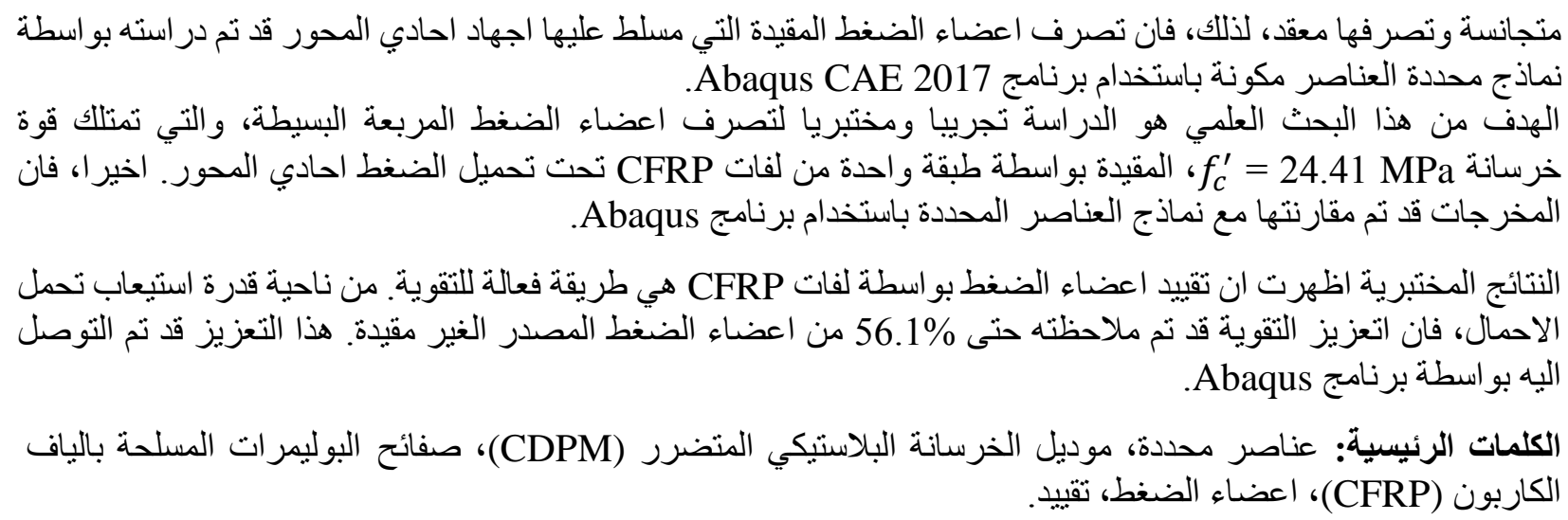

\section{INTRODUCTION}

One of the many cases that the structural engineer must tackle is the case where it is required to strengthen existing structural members. Strengthening of structural members are performed due to many reasons such as damage taken by the structural member resulting from natural disasters such as earthquakes, winds, floods, fire, ... etc., other reasons may include old age of building, an update in structural specifications complying certain factor to be met in any structural members, or change in the purpose of the structure itself. Columns (or compression members), being the most important structural member, which its failure can lead into a total collapse of the building, are the center focus of this study.

Increasing the load carrying capacity of structural elements, such as compression members or columns, can be done conventionally by increasing the concrete strength, dimensions of crosssection, or reinforcement and the like. But on the other hand, it is worthwhile to mention that ideas of increasing the load bearing capacity for existing compression member has raised to the surface recently. The complete lateral "clothing" of existing compression members by a sheet-like reinforcement attached to them by strong adhesives has been proven to provide certain improvement to strength properties of the compression members. However, there remains a problem that is the shape of compression members (columns) had proven to influence the increment of the load carrying capacity. Circular cross section is the best cross-sectional shape to employ (develop) full confinement effect of the sheets, ACI 440.2R-17.

This study revolves around strengthening square compression members by wrapping them externally with Carbon Fiber Reinforced Polymer (CFRP) wraps; and subjecting them to axial compressive loads, then, these members are modeled numerically using Abaqus CAE using finite element method. Thus, the axial behavior as well as strengthening effectiveness can be studied and analyzed for further understanding on this subject. According to Abdulhameed and Said (2019), many systems were developed in order to strengthen existing structures such as the replacement of structural members, by adding modern materials to improve the structural performance of individual elements and using post-tension rebar. A normal strength concrete considers as a brittle material with high compressive strength in comparison with the low tensile strength. To increase the tensile strength of concrete, small pieces of fibers could be added to concrete members, AlQuraishi, et al. ( 2019). 


\section{CONFINEMENT}

\subsection{Definition of Passive Confinement}

Ozbakkaloglu T. et al. (2012), defined passive confinement as the condition when FRP fibers do not exert immediate confininig pressrue (or the fibers do not cause confinement immediately) on the columns. But instead, fiber's confining pressure is only activated due to lateral dilation of the column under compression loading. Generally, tensile pressure starts to develop along hoop direction in the FRP wraps when the concrete, i.e. the member, starts to expand laterally (or dilate) due to the applied load. Therefore, it is clear that confinement pressure which develops in FRP wraps increase in proportionate with the dilation of the member. This behavior continues until the whole of the system fails. Failure in these systems can occur in two aspects, either rupture of CFRP wraps accompanied by concrete crushing, or premature concrete crush where CFRP wraps are not damaged but the concrete confined within the wraps is crushed.

\subsection{Confinement of Square and Rectangular Columns}

FRP sheets have weak flexural stiffness, thus, low transverse confining stress can be utilized in square or rectangular sections. At the edges and sharp corners of such sections; the high axial stiffness and the low flexural stiffness of FRP sheets develop stress concentration zones at these corners. Stress concentration is considered dangerous and it continues to develop until failure occurs at these regions generally by rupture of FRP sheets; while the stresses in the fibers lying along the perimeter of the section, i.e., along the sides of the section, are still much lower than the ultimate strength of the FRP fibers, Campione, et al. (2004).

As shown in Fig. 1, there is a reduction in the active confinement area. For a square or rectangular column with sharp corners, the confinement area starts at the corners in the form of a seconddegree parabola which has an initial slope of $45^{\circ}$. On the other hand, for square column with rounded corners with a radius $R_{c}$ (in $\mathrm{mm}$ ), the parabolic action is again assumed but in this case; the effective confinement area is larger than the case of sharp corners, Benzaid and Mesbah (2013).

In contrast to circular columns; FRP wraps exerts a non-uniform lateral stress on the square columns due to the non-uniform dilation of the square concrete column. Flat sides of the square column are subjected to lower pressure compared to the corners, i.e. the stress is concentrated at the corners. Therefore, due to the cross-sectional shape and due the non-uniform distribution of the confining stress, only a certain percentage of the whole cross-sectional area is confined effectively. Thus, the confinement efficiency in this case is lower than the case of circular columns. Furthermore, an additional reason for the lower efficiency is that in circular columns; the confining pressure depends mostly on the tensile stiffness of the FRP wraps, whereas in square columns; the confining pressure depends on the flexural stiffness of the FRP wraps, which is much lower than the tensile stiffness, Al-Khafaji (2016). 


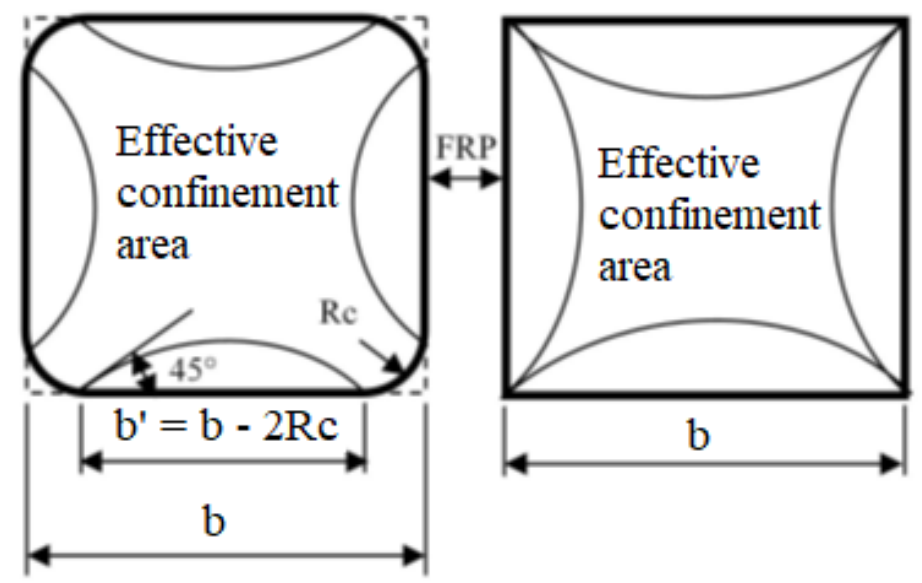

Figure 1. Active confined area for square column sections confined with FRP wraps (after Benzaid and Mesbah 2013).

\section{RESEARCH METHODOLOGY}

Four concrete compression members (with concrete strength of $f_{c}^{\prime}=24.41 \mathrm{MPa}$ ) were casted without any internal reinforcing steel. The specimens were divided into two groups:

- Two specimens without any confinement provided to them. These members are considered as the reference members. This group is titled R0, and the two members are referred to as R0-1 and R0-2.

- Two specimens confined with one layer of CFRP attached to them by strong adhesive such as epoxy resin. This group is titled $\mathrm{C} 1$, and the two specimens are referred to as $\mathrm{C} 1-1$ and C1-2.

All compression members had square cross section of dimension $100 \times 100 \mathrm{~mm}$, and a height of $300 \mathrm{~mm}$. All members were subjected to uniaxial compressive loading using concrete testing machine. Furthermore, two dial gauges were used to measure the lateral or side dilation at midheight of the compression members. These dial gauges were stationed on two opposite sides of the members, i.e. the in parallel positions but each one record dilation for different side of the member.

\section{EXPERIMENTAL MATRIX}

\subsection{Specimens Configuration}

Four compression members were casted without steel reinforcement. The four members had area of $100 \times 100 \mathrm{~mm}$, and a height of $300 \mathrm{~mm}$. The dimensions of the members were selected so that it does not in to the category of columns as defined by the ACI committee. ACI 318-14 to consider the compression members as short columns. The ACI has complied that any compression element for it to be considered as short column, then the ratio of height over least lateral dimension should be greater than 3 , and the member should be vertical or predominantly vertical orientation.

\subsection{Confining Process}

To achieve full confinement benefits or to achieve full confining pressure, CFRP wraps should be attached sufficiently and effectively on the compression members. To achieve this purpose, epoxy resin was used. First, epoxy resin was spread gently and evenly over the entire surface of the compression members, except at the top and bottom surfaces. After that, a single layer of CFRP 
wraps was placed on the surfaces where the resin was spread. Then, a rather small serrated steel roller was rolled over the CFRP wrap, this was done to achieve good impregnation of epoxy resin in the fibers of the wrap, and to avoid or exclude any air bubbles which may be created and trapped inside the epoxy. Fibers of the CFRP wraps, when attached or installed on the compression member surface, were oriented in the hoop direction. Finally, as a last step, an overlap, about $10 \mathrm{~cm}$, was made in the wraps. Resin was left for a time of 7 days for it to be fully dry.

\subsection{Material Properties}

Concrete used to create the compression members was normal strength concrete, and the cement was sulfate resisting cement. Furthermore, commercially available unidirectional CFRP sheets was used as confinement material. It was bought locally from a market. CFRP material that is used in laboratory experiments was uniaxial wraps where the fibers are oriented in one direction. For achieving attachment between CFRP and the members, epoxy resin was used. Tables $\mathbf{1}$ - $\mathbf{2}$ present properties of the materials used throughout this paper. Finally, it should be noted that many trial mixes were carried out and the mix ratio (volumetric mix ratio) mentioned in Table 1 were the one adopted to cast the columns in this study.

Table 1. Concrete mixture properties

\begin{tabular}{|l|l|}
\hline $\begin{array}{l}\text { Compressive strength of the concrete }\left(f_{c}^{\prime}\right) \text { used to } \\
\text { cast the square compression members }\end{array}$ & $24.41 \mathrm{MPa}$ \\
\hline $\begin{array}{l}\text { Concrete mix ratio for square compression } \\
\text { members }\end{array}$ & $\begin{array}{l}\text { Volumetric ratio of } 1: 1.5: 2.5 \\
\text { corresponding to: cement, sand, and } \\
\text { gravel respectively. }\end{array}$ \\
\hline Maximum size of grave or coarse aggregate & $12.5 \mathrm{~mm}$ \\
\hline Type of cement used for concrete mixture & Sulfate resisting cement \\
\hline PH of water used for concrete mixture & $6.8-7.2$ \\
\hline Lab temperature & $25^{\circ} \mathrm{C}$ \\
\hline
\end{tabular}

Table 2. Fiber properties of CFRP Wraps product

\begin{tabular}{|l|l|}
\hline Fiber tensile strength & $4900 \mathrm{~N} / \mathrm{mm}_{2}$ \\
\hline Fiber tensile modulus of elasticity & $230000 \mathrm{~N} / \mathrm{mm}_{2}$ \\
\hline Fiber elongation at break & $1.7 \%$ \\
\hline Fiber density & $1.80 \mathrm{~g} / \mathrm{cm}_{3}$ \\
\hline
\end{tabular}

\subsection{Instrumentation and Test Setup}

To monitor and measure the dilation of the compression members, two opposite-in-direction dial gauges were installed at midheight of the members. To exert compressive loading on the members, concrete compression machine was used. Plate 1. shows Test setup. 


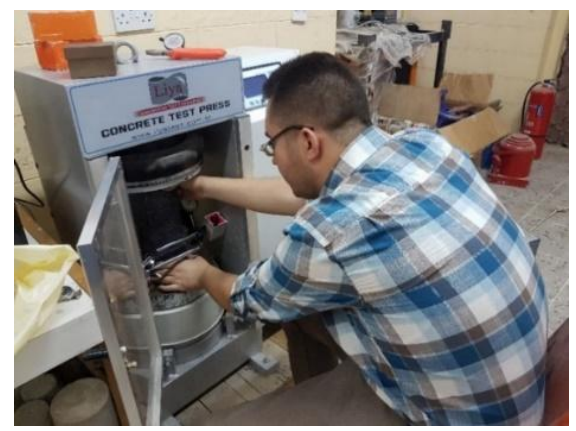

(a) Compression machine

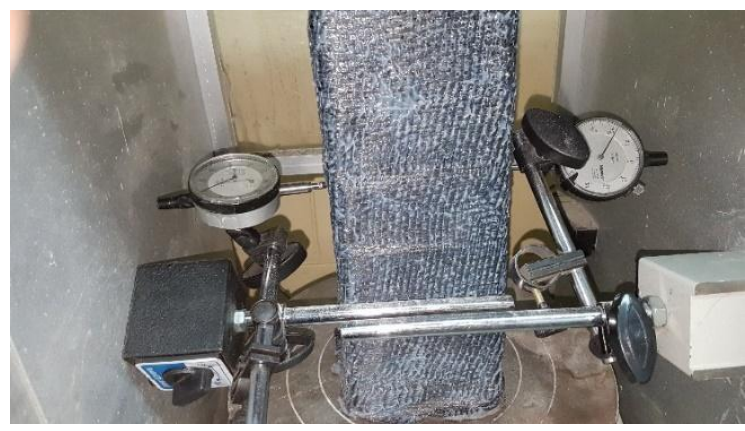

(b) Dial gauges

Plate 1. Installing dilation gauges for compression members

\section{MODELING OF CONCRETE MATERIAL}

In order to model concrete material for the compression members, the following constitutive relationships should be defined; elastic behavior of concrete and inelastic behavior of concrete.

\subsection{Elastic Behavior of Concrete}

Considering the elastic behavior of concrete, the concrete is modeled as an elastic and isotropic material. Upon identifying the elastic behavior of concrete as isotropic, two parameters to be defined which are modulus of elasticity and Poisson's ratio.

According to Nilson, et al. (2010), the axial compressive stress-strain diagram for the concrete is regarded to be almost linear, i.e., concrete behaves elastically. However, this elastic behavior of concrete is observed at low stresses and it continues in the same manner up to an approximate stress value of $0.5 f_{c}^{\prime}$ as shown in Figure. After the value of $0.5 f_{c}^{\prime}$, the stress-strain curve behaves in an inelastic manner where stresses are no longer linearly proportionated to strains.

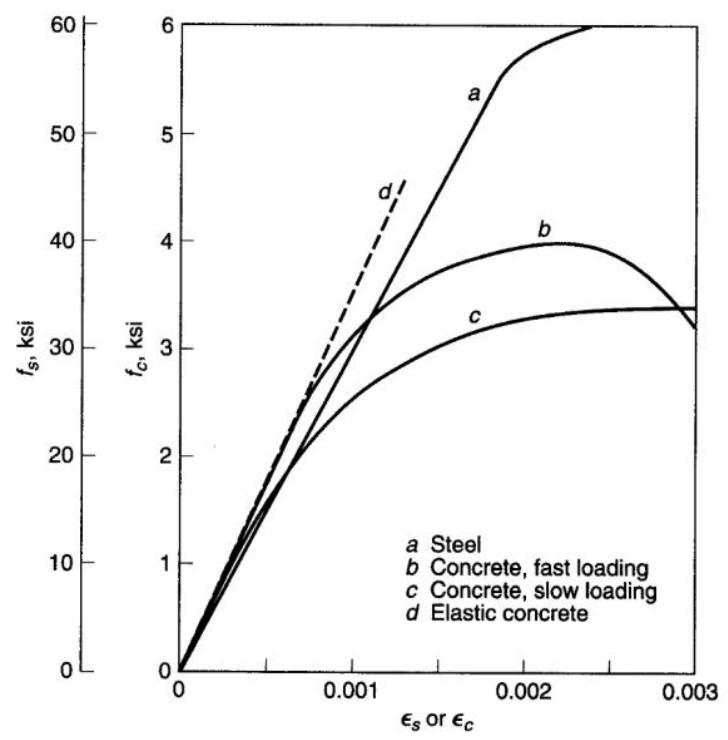

Figure 2. Uniaxial compressive stress-stain diagram (after Nilson, et al., 2010).

Due to the fact that the concrete has a stress strain curve on which there is no definite proportional limit, it is rather a difficult task to obtain the modulus of elasticity. However, ACI 318-14 allows the use of Eq. (1) to calculate the modulus of elasticity of concrete. 


$$
E=4700 \sqrt{f_{c}^{\prime}}
$$

where:

$E$ : modulus of elasticity of concrete, $\mathrm{MPa}$

$f_{c}^{\prime}$ : specified compressive strength of concrete (of standard concrete cylinder), MPa

When identifying Poisson's ratio (v) for concrete, a value between (0.15-0.2) should be selected, Dere \& Koroglu (2017). Thus, the parameters used to define elastic behavior of concrete material is $E=23221 \mathrm{Mpa}$ (substituting $f_{c}^{\prime}=24.41 \mathrm{Mpa}$ in Eq. (1)), and $v=0.2$.

\subsection{Inelastic Behavior of Concrete}

For modeling the inelastic behavior of concrete material, there are majorly two types of material models that can be used to simulate the properties and characteristics of concrete. The two models are known as Concrete Damaged Plasticity Model (CDPM) and Concrete Smeared Cracking Model (CSCM).

Concrete Damaged Plasticity Model (CDPM) possesses the ability to represent or describe the complete inelastic behavior of concrete material for both cases, tension and compression. CDPM also takes into consideration damage parameters. CDPM assumes two modes of failure that may happen to concrete material. The two failure modes are first the tensile cracking and second the compressive crushing, Wahalathantri et al. (2011).

\subsection{Parameters and Variables of CDPM}

The following parameters should be defined: dilation angle $(\psi)$ (measured in degrees), flow potential eccentricity (e), ratio of initial equibiaxial compressive yield stress to initial uniaxial compressive yield stress $\left(f_{b_{0}} / f_{c_{0}}\right)$, the coefficient $k$, and viscosity $(\mu)$. Table 3 lists these parameters.

Table 3. CDPM Parameters.

\begin{tabular}{|c|c|c|c|c|c|}
\hline \multicolumn{6}{|c|}{ ABAQUS built-in default values } \\
\hline Parameters & $\psi$ & $e$ & $f_{b_{0}} / f_{c_{0}}$ & $k$ & $\mu$ \\
\hline Values & User defined & 0.1 & 1.16 & 0.6667 & 0.0 \\
\hline \multicolumn{6}{|c|}{ Parameters adopted in this study } \\
\hline Parameters & $\psi$ & $e$ & $f_{b_{0}} / f_{c_{0}}$ & $k$ & $\mu$ \\
\hline Values & 55 & 0.1 & 1.16 & 0.7 & $10^{-5}$ \\
\hline
\end{tabular}

The data for compressive and tensile behavior come from uniaxial compression and uniaxial tension test respectively, but the plasticity section need five parameters such as dilation angle ( $\Psi)$ which is the dilation angle measured in the p-q plane at high confining pressure, eccentricity (e) is a parameter referred to as the eccentricity, that defines the rate at which the flow potential function approaches the asymptote (the flow potential tends to a straight line as the eccentricity tends to 
zero), fb0/fc0 is a ratio of the strength in the biaxial state to the strength in the uniaxial state, and $\mathrm{k}$ is the ratio of the Mises equivalent effective stress on the tensile meridian, Labibzadeh, and Hamidi, R. (2016). Finally, it should be noted that the damage parameters dt and dc are taken equal to zero.

It is worth to mention that Genikomsou (2015) modeled two reinforced concrete beams, with and without stirrups, using CDPM and compared the data results from Abaqus with experimental results. He concluded that for the beam model which had no stirrups, the optimum dilation angle which captured the behavior of the beam was $30^{\circ}$. While for the beam model which had stirrups reinforcement, the optimum dilation angle which captured the behavior of the beam was $42^{\circ}$. Thus, he concluded that confined concrete requires high value of dilation angle. In this study, the dilation angle was taken equal to $55^{\circ}$ for compression members fully externally confined by CFRP wraps.

\subsection{Compressive Behavior of Concrete}

For the complete benefit of adopting CDPM, ABAQUS requires the user to define the axial compressive behavior, precisely the yield stress versus the inelastic strain, of concrete. Many equations have been proposed by different researchers to describe the compressive behavior of concrete including the softening area on stress-strain curve. For full description of stress-strain behavior of concrete in CDPM, mathematical Eq. (2) and (3), which were suggested and used by Chaudhari \& Chakrabarti (2012), are used in this paper. The two mathematical equations represent the hardening zone of stress-strain curve as a parabola and the softening zone as a straight line respectively.

$$
\begin{array}{ll}
\text { For } 0<\varepsilon_{c}<\varepsilon_{c}^{\prime} & \frac{f_{c}}{f_{c}^{\prime}}=2 \times \frac{\varepsilon_{c}}{\varepsilon_{c}^{\prime}}\left(1-\frac{\varepsilon_{c}}{2 \varepsilon_{c}^{\prime}}\right) \\
\text { For } \varepsilon_{c}^{\prime}<\varepsilon_{c}<\varepsilon_{c u} & \frac{f_{c}}{f_{c}^{\prime}}=1-0.15\left(\frac{\varepsilon_{c}-\varepsilon_{c}^{\prime}}{\varepsilon_{c u}-\varepsilon_{c}^{\prime}}\right)
\end{array}
$$

where:

$f_{c}$ : compressive stress, MPa.

$f_{c}^{\prime}$ : maximum stress exerted on concrete, $\mathrm{MPa}$.

$\varepsilon_{c}$ : strain corresponding to stress $f_{c}, \mathrm{~mm} / \mathrm{mm}$.

$\varepsilon_{c}^{\prime}$ : strain corresponding to maximum stress $f_{c}^{\prime}, \mathrm{mm} / \mathrm{mm}$.

$\varepsilon_{c u}$ : ultimate strain defined at concrete failure, $\mathrm{mm} / \mathrm{mm}$.

According to Nilson, et al. (2010), the ultimate strain of normal concrete is $\varepsilon_{c u}=0.003$. Thus, by considering a strength value of $f_{c}^{\prime}=24.41 \mathrm{MPa}$, while performing equations (2) and (3), compressive stress-strain diagram curve is obtained as shown in Figure 3. 


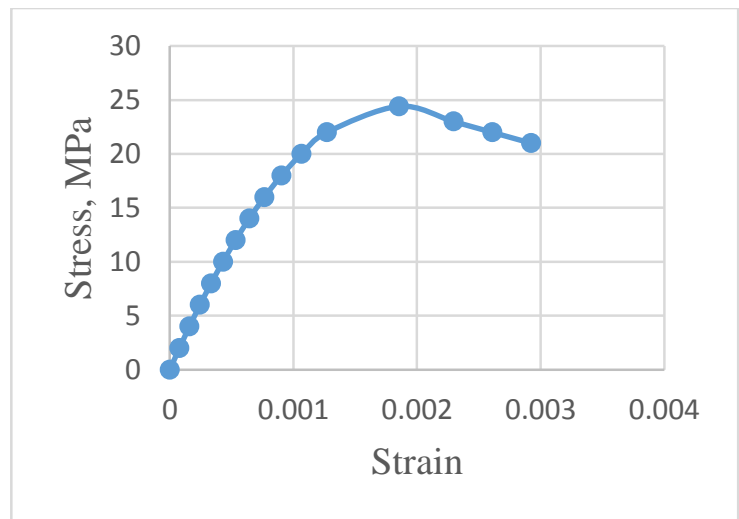

Figure 3. Compressive stress-strain diagram.

In CDPM, it is only required to define a single point (or a table of points) of yield stress versus inelastic strain. By using Eq. (2) and (3), one can obtain full compressive behavior of concrete material. However, to obtain the yield stress versus inelastic strain, it is necessary to define the value of yield stress. Nilson, et al. (2010), mentioned that up to (50-60)\% of $f_{c}^{\prime}$, the stress-strain curve is almost nearly elastic. Therefore, since the strength is $f_{c}^{\prime}=24.41 \mathrm{MPa}$, then the yield stress is considered as $12 \mathrm{MPa}$, which is almost equal to $50 \%$ of $f_{c}^{\prime}$.

By using Eq. (2), the strain corresponding to yield stress (corresponding to $f_{c}=12 \mathrm{MPa}$ ) is calculated and its strain value is $\varepsilon_{c}=0.00053$. Therefore, yield stress and inelastic strain are both determined. It is important to note that any stress-strain diagram must satisfy Eq. (4). Figure , demonstrates the zones of elastic and inelastic strains of the stress-strain diagram.

$$
\varepsilon_{c u}=\varepsilon_{e}+\varepsilon_{i e}
$$

or

$$
\varepsilon_{\text {compression ultimate }}=\varepsilon_{\text {elastic }}+\varepsilon_{\text {inelastic }}
$$

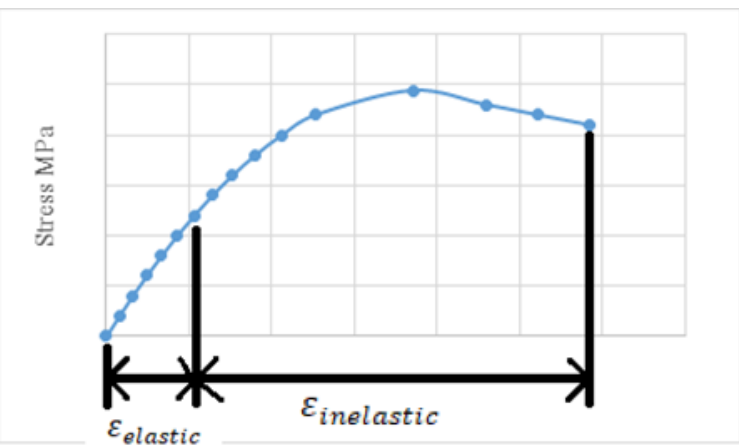

Figure 4. Compressive stress vs elastic and plastic strain

It is worth to mention that at $\varepsilon_{c}=\varepsilon_{e}$, then $\varepsilon_{i e}=0$. Thus, at yield stress, $f_{c}=12 \mathrm{MPa}$, the inelastic strain $\varepsilon_{i e}=0$. To obtain the subsequent values of $\varepsilon_{i e}$ corresponding to $f_{c}>$ yield stress, i.e., $f_{c}>12 \mathrm{MPa}$, Eq. (5) is adopted.

$$
\varepsilon_{i e}=\varepsilon_{c}-\varepsilon_{e}
$$

where

$\varepsilon_{i e}$ : inelastic strain corresponding stress $f_{c} \geq$ yield stress, $\mathrm{mm} / \mathrm{mm}$. 
$\varepsilon_{c}$ : strain corresponding to stress $f_{c}, \mathrm{~mm} / \mathrm{mm}$.

$\varepsilon_{e}$ : elastic strain corresponding to yield stress, $\mathrm{mm} / \mathrm{mm}$.

Regarding the aforementioned case of $f_{c}^{\prime}=24.41 \mathrm{MPa}$, the elastic strain $\varepsilon_{e}=0.00053$. Thus, by substituting the correct values into Eq. (5), the inelastic strain $\varepsilon_{i e}$ corresponding to $f_{c}>$ yield stress, can be easily determined.

\subsection{Tensile Behavior of Concrete}

When using CDPM, it is essential to define the tensile behavior of concrete material. Carreira \& Chu (1986), proposed a mathematical Eq. (6) to describe the tensile behavior of concrete material. Dere \& Koroglu (2017), proposed an assumption that defines the tensile stress-strain proportionality curve in the hardening (ascending) zone of the curve. The proportionality was assumed up to a maximum tensile stress $f_{t}^{\prime}$. Considering the softening (descending) part, stressstrain diagram also follows equation (6) to (8) that were proposed by Carreira \& Chu in (1986).

$$
\frac{f_{t}}{f_{t}^{\prime}}=\frac{\beta \times \frac{\varepsilon_{t}}{\varepsilon_{t}^{\prime}}}{\beta-1+\left(\frac{\varepsilon_{t}}{\varepsilon_{t}^{\prime}}\right)^{\beta}}
$$

where

$f_{t}$ : applied stress, MPa.

$f_{t}^{\prime}$ : maximum tensile stress, can be considered as concrete's tensile strength, MPa.

$\varepsilon_{t}$ : strain corresponding to stress $f_{t}, \mathrm{~mm} / \mathrm{mm}$.

$\varepsilon_{t}^{\prime}$ : strain corresponding to maximum stress $f_{t}^{\prime}, \mathrm{mm} / \mathrm{mm}$.

$\beta$ : parameter that depends on the shape of the stress-strain curve.

Maximum tensile stress for normal weight concrete, can be calculated from equation (7). Tensile strain corresponding to maximum tensile stress, can be calculated from equation (8).

$$
\begin{gathered}
f_{t}^{\prime}=0.33 \sqrt{f_{c}^{\prime}} \\
\varepsilon_{t}^{\prime}=\frac{\varepsilon_{c}^{\prime}}{10}
\end{gathered}
$$

Thus, $\varepsilon_{t}^{\prime}$ is $\frac{1}{10}$ of the strain corresponding to maximum compressive stress $\left(\varepsilon_{c}^{\prime}\right)$ acquired from compressive stress-strain relationship. Additionally, $\varepsilon_{t}^{\prime}$ can also be assumed equals to $\varepsilon_{t}^{\prime}=$ 0.0002 . Furthermore, it is possible to assume that the parameter $\beta$ can have the same value for tension and compression. Therefore, $\beta$ for tension and compression can be determined by solving Eq. (9) proposed by Carreira \& Chu (1986).

$$
\beta=\left(\frac{f_{c}^{\prime}}{32.4}\right)^{3}+1.55
$$

As a conclusion, by using sets of Eq. (6) to (9), it is possible to obtain tensile stress-strain behavior for normal concrete material. Figure demonstrates the tensile stress-strain curve. The ultimate tensile strain has a value of $\varepsilon_{t u}=0.002$ for normal weight concrete. 


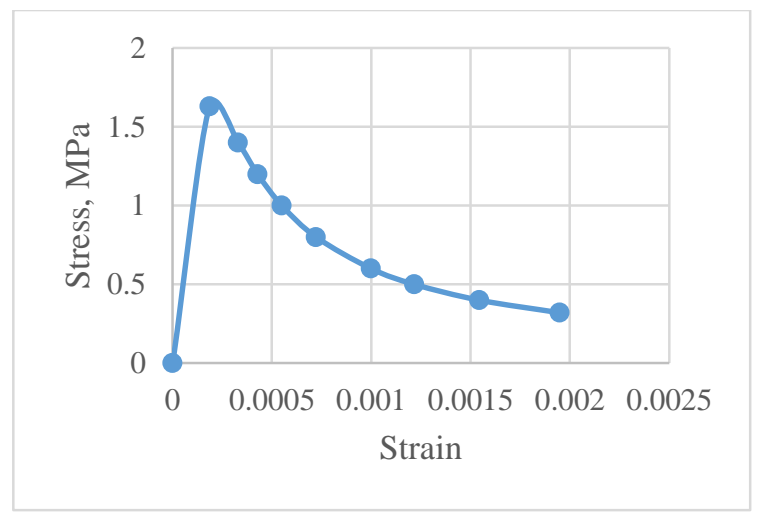

Figure 5. Tensile stress-strain diagram.

Similar to the case of compressive behavior, ABAQUS CDPM does not require a full definition of the tensile behavior of concrete material, but instead, CDPM requires the definition of one coordinate (or table of coordinates) of yield stress versus cracking strain. Since stress-strain curve was assumed linear up to the point of maximum tensile stress, then the maximum tensile stress $f_{t}^{\prime}$ is be considered as the yield stress; and the corresponding strain is considered as the elastic strain, i.e., $\varepsilon_{\text {elastic }}=\varepsilon_{t}^{\prime}=0.0002$. In this manner, the yield stress and cracking strain can be determined. It should be noted that any tensile stress-strain diagram should satisfy Eq. (10). Figure demonstrates the zones of elastic and cracking strains on the tensile stress-strain curve.

$$
\varepsilon_{t u}=\varepsilon_{e}+\varepsilon_{\text {crack }}
$$

or

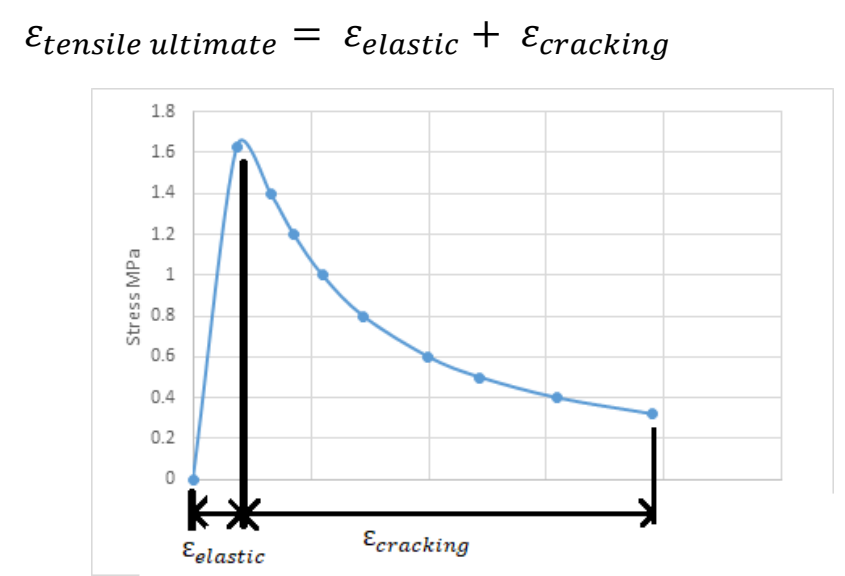

Figure 6. Tensile stress vs elastic and plastic strain.

It should be noted that based on the concrete with a strength of $f_{c}^{\prime}=24.41 \mathrm{MPa}$, at peak stress where $\varepsilon_{t}=\varepsilon_{e}=0.0002$, then $\varepsilon_{\text {crack }}=0$. Therefore, at yield stress (at $f_{t}=f_{t}^{\prime}=1.6304$ ), cracking strain corresponding to this yield stress is zero, i.e., $\varepsilon_{\text {crack }}=0$. In order to obtain the subsequent values of cracking strain $\varepsilon_{\text {crack }}$ corresponding to $f_{t}<$ yield stress, i.e. $f_{t}<1.6304 \mathrm{MPa}$, Eq. (11) shall be used. According to Carreira \& Chu (1986), the value of ultimate tensile strain for normal weight concrete is $\varepsilon_{t u}=0.002$.

$$
\varepsilon_{\text {crack }}=\varepsilon_{t}-\varepsilon_{e}
$$

where 
$\varepsilon_{\text {crack }}$ : cracking strain corresponding to stress $f_{t}, \mathrm{~mm} / \mathrm{mm}$.

$\varepsilon_{t}$ : strain corresponding to $f_{t}, \mathrm{~mm} / \mathrm{mm}$.

$\varepsilon_{e}$ : elastic strain corresponding to peak stress or corresponding to $f_{t}, \mathrm{~mm} / \mathrm{mm}$.

$\varepsilon_{t u}:$ ultimate strain at failure, $\mathrm{mm} / \mathrm{mm}$.

\section{VALIDATION OF THE ADOPTED COMPRESSIVE STRESS-STRAIN EQUATION}

Eq. (2) and (3) which are adopted to describe compressive stress-strain behavior in CDPM, shall be validated to determine if they are able to capture the true behavior of concrete in compression. In order to validate these equations; experimentally obtained stress-strain curve should be compared with stress-strain curve obtained by using these equations. Fig. 7 shows a comparison between two curves. First, is a stress-strain relation adopted from the work of Carreira and Chu (1985). This plotted stress-strain curve is for a standard cylinder of $15 \times 15 \times 30 \mathrm{~cm}$. Second, a stressstrain relation obtained by solving Eq. (2) and (3).

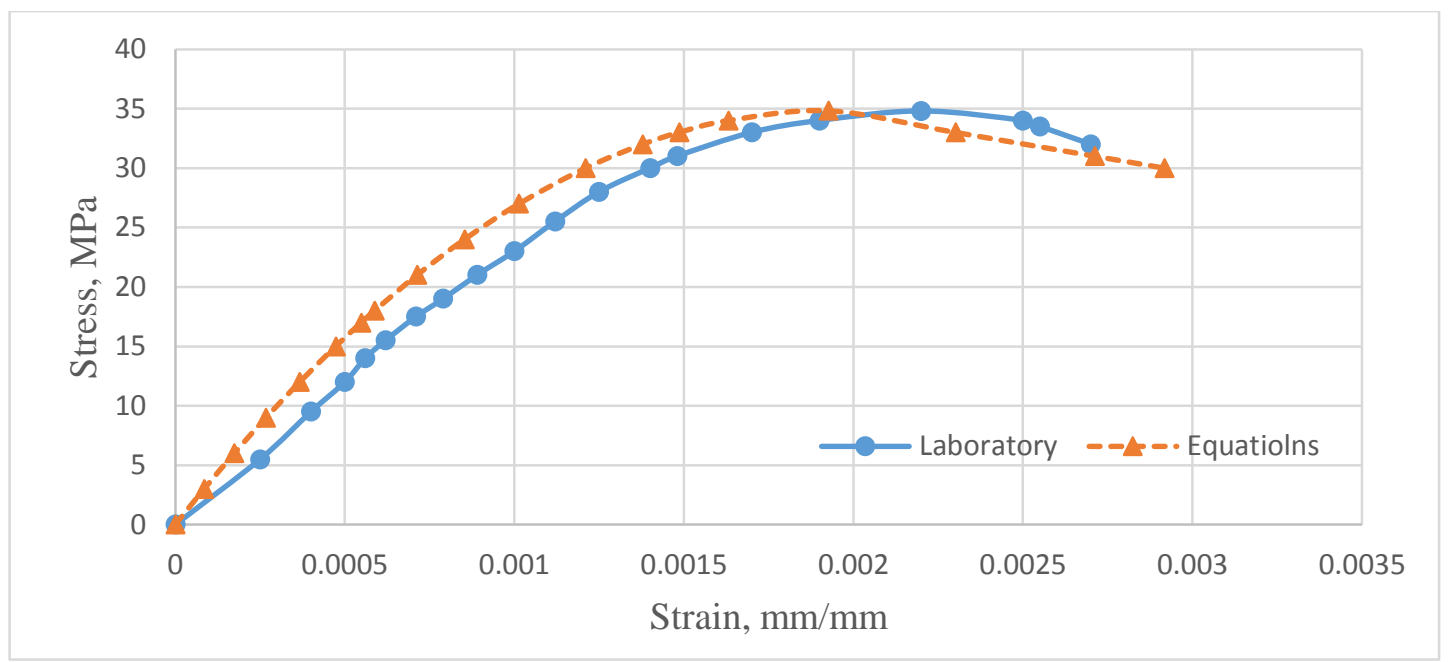

Figure 7. Compressive stress-strain curve of a standard cylinder, comparison between numerical equations of Chaudhari and Chakrabarti (2012) and laboratory experiments.

As seen in Fig. 6, the two curves are similar with a very good compatibility. Thus, Eq. (2) and (3) are reliable and can be adopted to describe the compressive behavior of concrete in compression.

\section{MODELING OF CFRP MATERIAL}

Since CFRP wraps have only one purpose and this purpose is to provide external confinement, and since the wraps cannot support neither lateral forces nor compressive forces but can only support tensile forces, the CFRP wraps were modeled as 3D shell elements. Modeling of CFRP wraps as shell elements inherits the assumption that the wraps shall support plane stresses only. This case is true for CFRP wraps because only plane stresses are developed in the wraps. Since only axial compression loads are applied and no lateral loads are applied to the compression members, thus, the choice of shell element is a suitable choice to model the wraps. However, due to the fact that the wraps only support tension stresses (the wraps provides no support to compressive stresses), thus, when defining the material of CFRP wraps, only tension stiffness was 
defined. In addition, for the wraps to act as confinement members during loading and analysis procedure, it is important to specify a zero value for Poisson's ratio, Xiao \& Teng (2010).

The definition "lamina elastic material" is a special case of the definition of orthotropic elastic material. However, in ABAQUS lamina is used to specify orthotropic elastic properties in plane stress condition. This definition is convenient for CFRP wraps because they act as confining elements which only develop plane stresses. When selecting lamina elastic material, ABAQUS CAE requires the definition of few parameters and characteristics. These parameters include $E_{1}$, $E_{2}, N u_{12}, G_{12}, G_{13}$, and $G_{23}$. These parameters can be obtained from datasheet of the product. The parameters introduced in ABAQUS are listed below. Finally, this choice of lamina elastic material to be selected to define CFRP wraps was used by Tipnis (2015).

$E_{1}=225000 \mathrm{MPa}$.

$E_{2}=1 \mathrm{MPa}$ (Low value is assumed, since Abaqus does not permit a zero value).

$N u_{12}=0$

$G_{12}=0.1 \mathrm{MPa}$ (For same reason of $\left.\mathrm{E}_{2}\right)$.

$G_{13}=115000 \mathrm{MPa}$.

$G_{23}=0.1 \mathrm{MPa}$ (For same reason of $\mathrm{E}_{2}$ ).

\section{DEFINING PARTS AND ELEMENTS}

For modeling concrete compression members, hex (hexagonal) element type has been selected. Thus, a 3-dimensional cubic brick continuum element was selected to model concrete compression members. Also, reduced integration process was performed during analysis process for each single element. C3D8R element has been adopted for modeling of square concrete members with reduced integration process for analysis.

CFRP wrap was modeled as a 3D shell part due to the fact that they resist only in-plane diagonal tension stress. Regarding the elements assigned for the wraps, S4R element was adopted. This element is characterized as a 4-node element with reduced integration. For the type of stress developed in the wraps were plane stresses. Therefore, to achieve this type of stresses, the element was chosen to be analyzed as a shell.

\section{INTERACTION AND BOUNDARY CONDITIONS}

Interaction between CFRP wraps and compression members were modeled using tie constraint. This option means that there is a full bonding in all degrees of freedom between the connected elements, i.e. concrete and CFRP. This type of interaction was adopted by Lin \& Teng (2013). A uniform compressive stress was subjected to the compression member models. Furthermore, when simulating boundary conditions BC, the entire bottom surface was restrained by pin supports. Therefore, movement of the bottom of the models was restricted from translation motion in three dimensions. Similar BC were used by several researchers such as Campione, et al. (2004) .

\section{RESULTS AND DISCUSSION}

10.1. Square compression members with no external confinement

This group contains two compression members with titles R0-1 and R0-2. Plate 2 presents failure modes for the two specimens. 


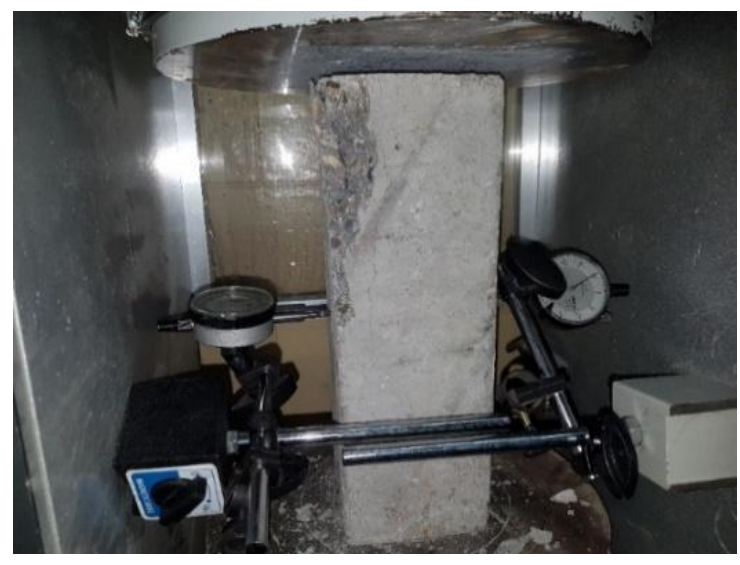

(a) Compression member R0-1 at failure

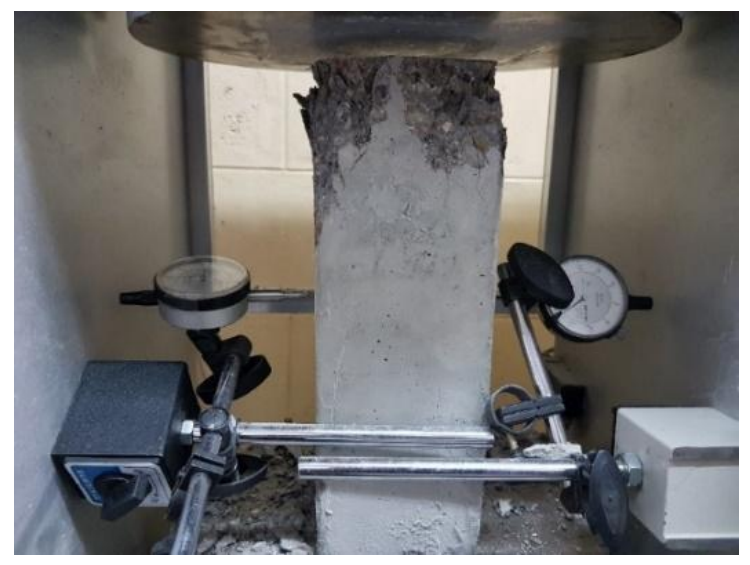

(b) Compression member R0-2 at failure

Plate 2. Modes of failure of compression members R0

In the case of unconfined compression members, the strength of the two specimens was 20.94 $\mathrm{MPa}$ for specimen R0-1 and 20.52 MPa for specimen R0-2. Thus, the average strength for specimens R0 is $f_{c o}^{\prime}=20.73 \mathrm{MPa}$.

It is noticed the compression members failed by crushing of the concrete material at top zones and precisely at the edges. Members failed by crushing of concrete, this is the general failure mode for compression members. The lateral displacement was measured by the two dial gauges. The two dial gauges recorded a rather small lateral expansion at midheight of the two specimens. Never the less, this lateral expansion did not influence the overall behavior of the compression members because the members were designed to be compression members and their failure was that of compression members, i.e. failed by crushing. Figure and $\mathbf{9}$ show the load displacement curve obtained from the two laboratory members plotted in addition to the load displacement curve obtained from FE models of ABAQUS software.

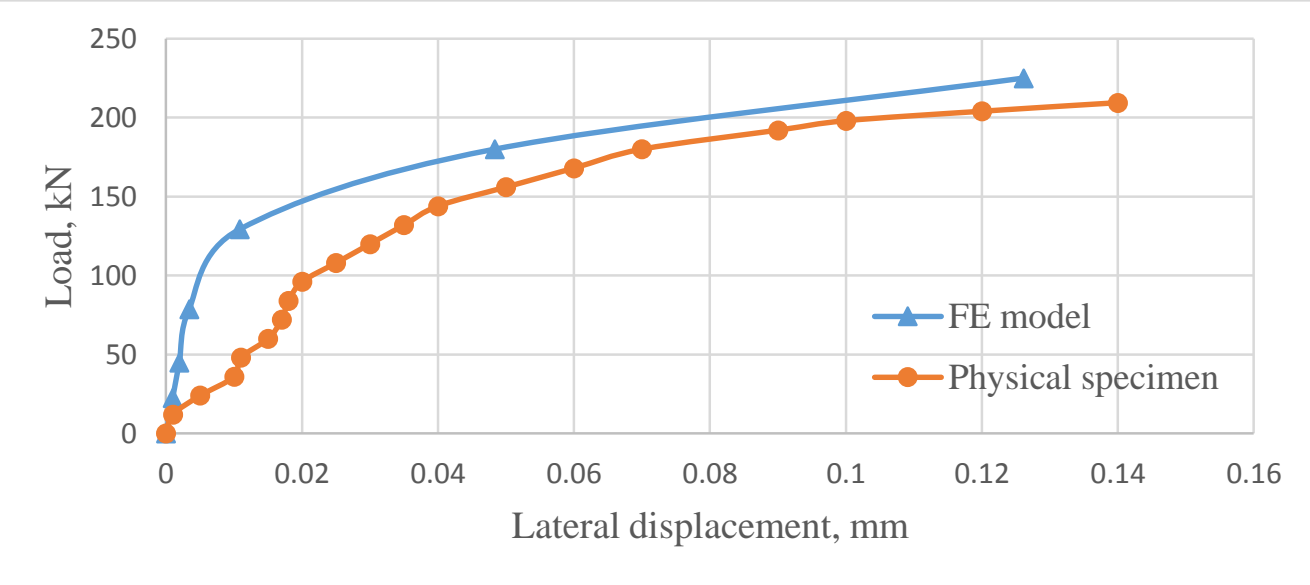

Figure 8. Load-displacement behavior of compression member R0-1. 


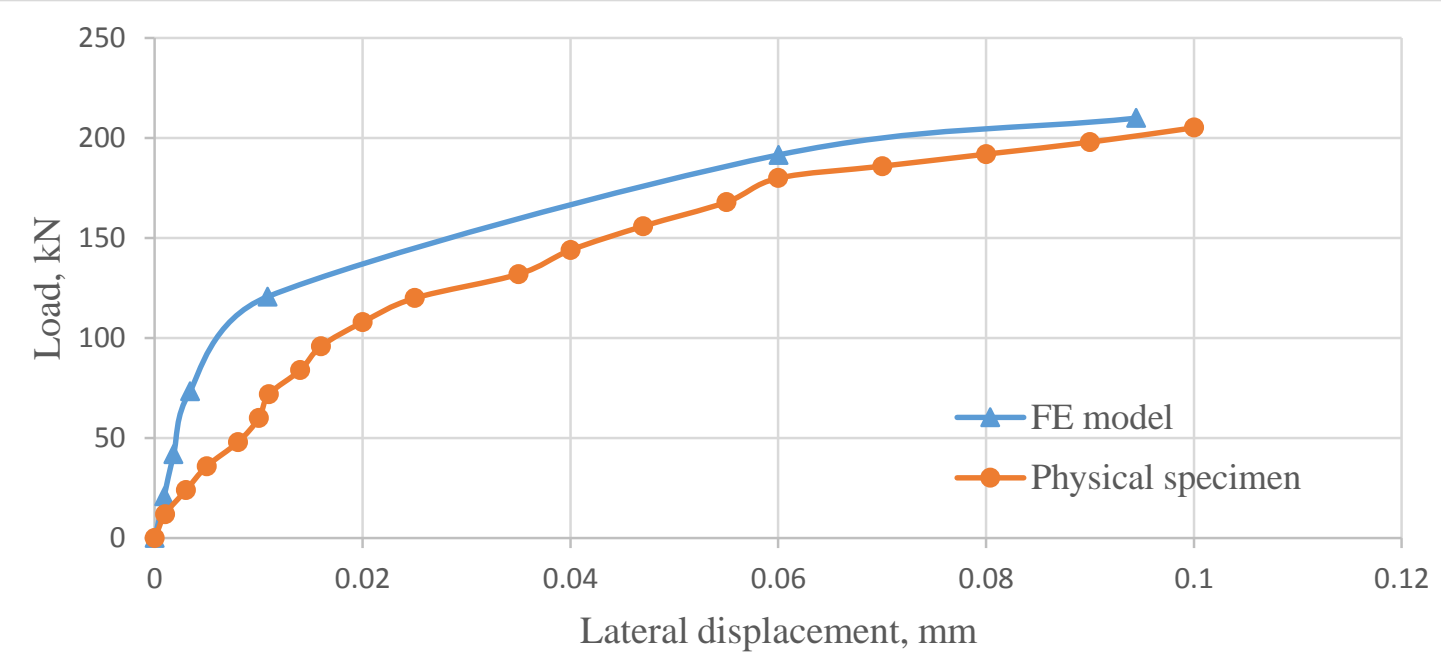

Figure 9. Load-displacement behavior of compression member R0-2.

It can be seen from the two figures that the FE curve overlies the experimental one. Up to a strain of 0.06 the difference between the two curves is more or less considered moderate, but then after the two curves get close and rather converge. The general trend of behavior for the two curve are similar.

\subsection{Square compression members confined with one layer of CFRP wraps}

This group contains two compression members with titles $\mathrm{C} 1-1$ and $\mathrm{C} 1-2$. Plate 2 presents failure modes for the two members. By observing failure modes of the two members, it is apparent that they failed prematurely. In other words, the CFRP did not rupture, i.e. CFRP wraps did not reach its ultimate strain, while the confined concrete crushed inside the wraps. Furthermore, because failure was a premature failure, the crushed concrete could not be observed by eye, yet it remained trapped inside the CFRP wraps. However, after closer examination, a slight and noticeable bulge in the two compression members was observed. This indicates that indeed the concrete was crushed and was trapped inside the CFRP wraps. It should be mentioned that similar mode of failure for CFRP-confined columns was experienced by also by Benzaid and Mesbah (2013).

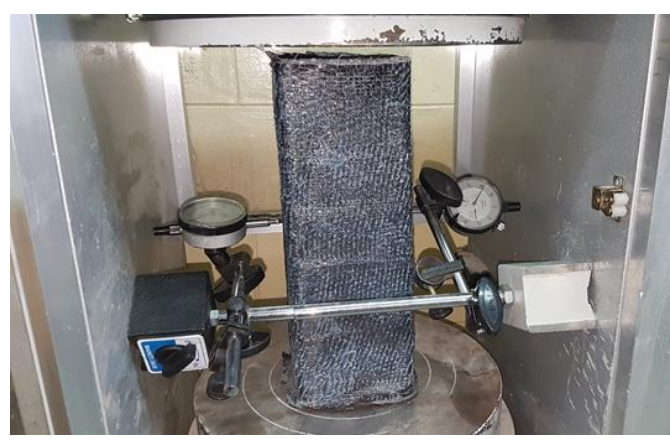

(a) Compression member $\mathrm{C} 1-1$ at failure

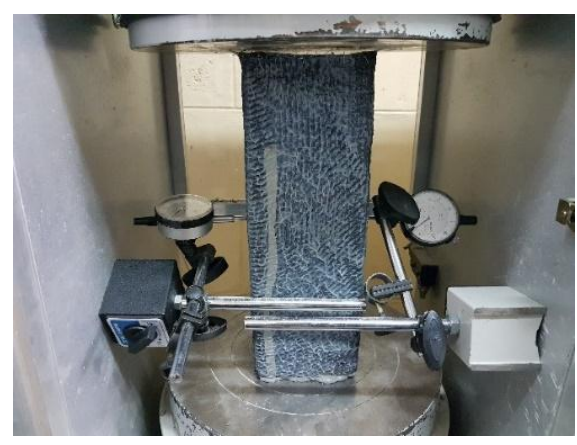

(b) Compression members $\mathrm{C} 1-2$ at failure

Plate 3. Modes of failure of compression members C1.

In the case of unconfined compression members, the strength of the two specimens was $20.94 \mathrm{MPa}$ for specimen R0-1 and $20.52 \mathrm{MPa}$ for specimen R0-2. Thus, the average strength for specimens $\mathrm{R} 0$ is $f_{c o}^{\prime}=20.73 \mathrm{MPa}$. For the case of FRP-confined compression members, the strength of the 
two members was $31.19 \mathrm{MPa}$ for member $\mathrm{C} 1-1$ and 33.53 for member $\mathrm{C} 1-2$. Thus, the average strength for members $\mathrm{C} 1$ is $f_{c c}^{\prime}=32.36 \mathrm{MPa}$.

Thus, by providing confinement for square compression members provided by wrapping the members externally by one CFRP layer, an increase in load carrying capacity was up to $56.1 \%$. This high enhancement in load carrying capacity is attributed to the premature failure mode of the C1 compression members. Where, for this mode of failure, the confined concrete was crushed while the FRP layer did not ruptured. It should be mentioned that similar large enhancement in load carrying capacity of confined compression members was reached in the study of the two researchers, Khan and Fareed (2012). In their work, the specimens were short square concrete columns fully confined by a single layer of CFRP wraps. Also, the columns in their study were also subjected to uniaxial compressive loading. In their experiments, the two columns also failed prematurely where concrete crushed while FRP was not ruptured. The enhancement in load carrying capacity reached by these two researchers was up to $36 \%$.

Full strength of the fibers in CFRP wraps were not fully developed during testing, this is due to the fact that the wraps resist only tensile stresses and they do not resist flexural stresses or they do not have flexural stiffness. As seen from the work of Campione et al. (2004), confined square columns failed by rupture of CFRP fibers at the corners of the column, thus, proving that the strength of the fibers were not developed along the sides of the columns but only in the corners where stress was concentrated.

Figure and $\mathbf{1 1}$ show the load displacement curve obtained from the two laboratory compression members plotted in addition to the load displacement curve obtained from FE models of ABAQUS software.

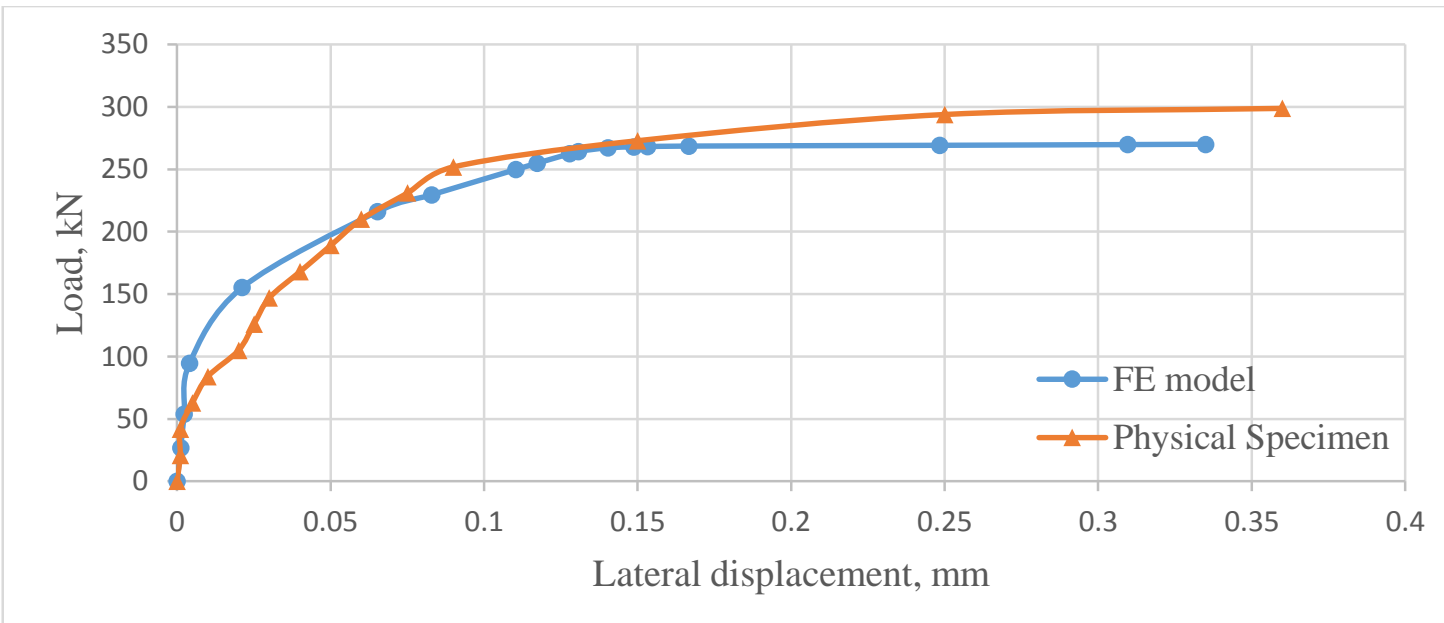

Figure 10. Load-displacement curve of compression members C1-1. 


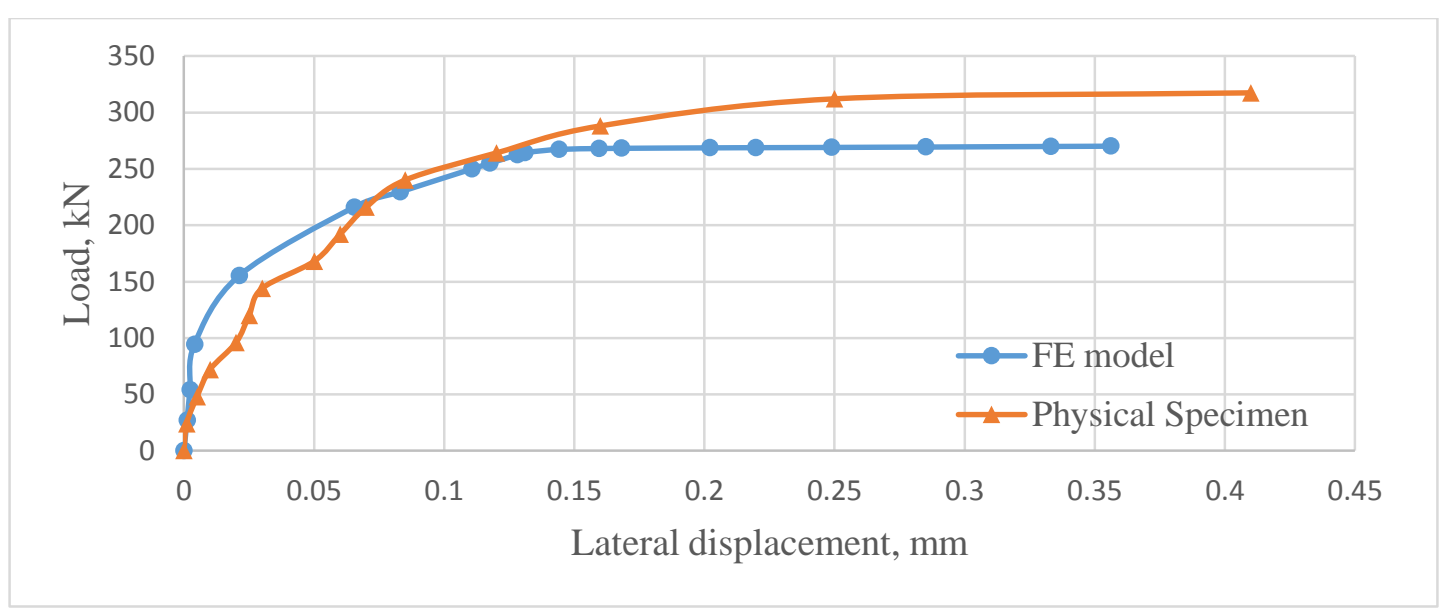

Figure 1. Load-displacement curve of compression members C1-2.

From the two Fig. 10 and 11, it observed that the overall behavior of the two curves in Fig. 10 and 11 are similar and at good convergence. The curves in both figures meet each other more than once, then, after a displacement of $0.16 \mathrm{~mm}$, the two curves (in both figures) seems to diverge from one another. However, the curves (in Fig. 10 and 11) seems to exhibit an elastic behavior after reaching displacement of $0.21 \mathrm{~mm}$. Where after $0.21 \mathrm{~mm}$, the curves seem to start flatten or leveling, i.e. for very small load the displacement increase dramatically. As it is clear from the bar chart Fig. 12 the load bearing capacity is essentially increased when the square specimen is wrapped with only one layer of CFRP wraps.

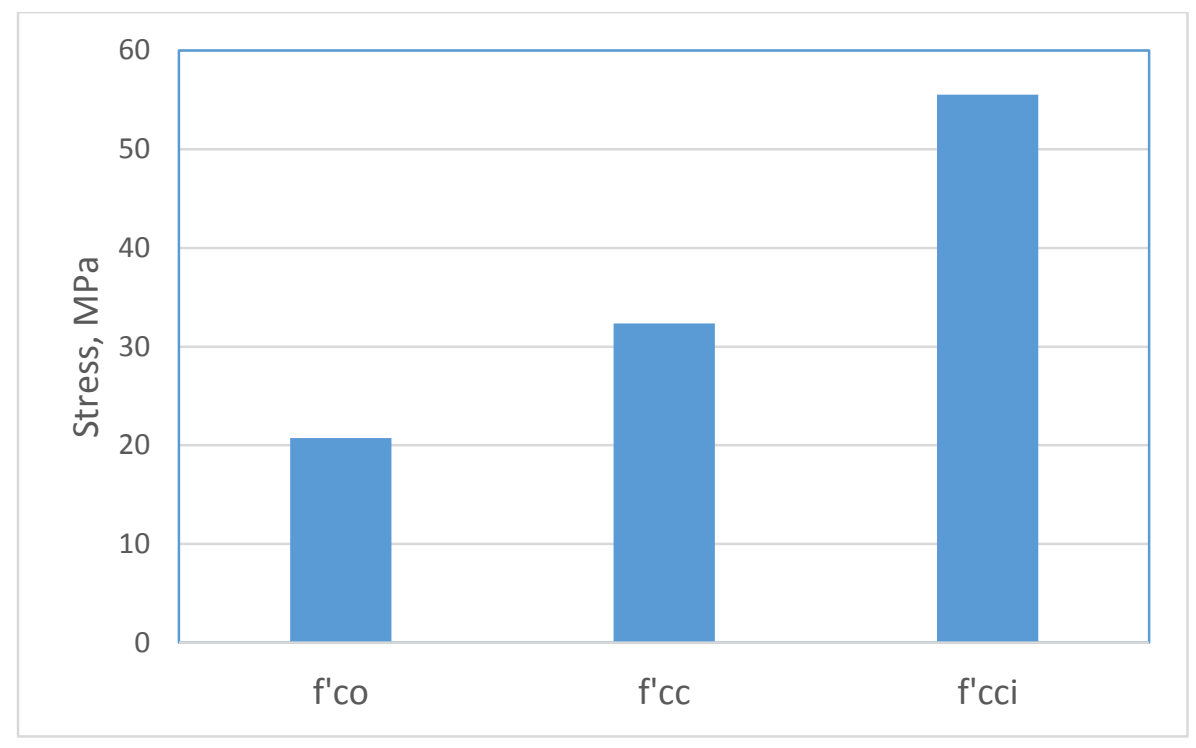

Figure 12. Bar chart that illustrates the maximum average stress, $f_{c o}^{\prime}$ and $f_{c c}^{\prime *}$.

$* f_{c o}^{\prime}$ : Average maximum stress applied on the reference non-confined square compression members, MPa.

$f_{c c}^{\prime}$ : Average maximum stress applied on CFRP confined square compression members, $\mathrm{MPa}$. 


\section{PARAMETRIC STUDY}

In this section, square confined compression member C1-1 is confined in this section, for the purpose of parametric study, by different number of CFRP layers. Thus, FE model titled C1-1 shall be wrapped with one, two, and three layers of CFRP. Then load-displacement behavior is observed and plotted for each layer. Fig. 13 presents load-displacement diagram for three models $\mathrm{C} 1-1$, but each one with different number of CFRP layers as confinement. The three FE models are titled C1-1, C2-1, and C3-1 representing square compression member confined by one, two, and three layers respectively. Finally, the physical laboratory member R0-1 was introduced to the diagram for further understanding and observation.

It is observed that the three FE models behave identical to each other until a displacement of 0.02 is reached. Beyond this value, the three models start to divers. At the final load of $270 \mathrm{kN}$, it is observed that the model confined with one layer of CFRP underwent large displacement compared to the other two FE models. For this model confined with one layer, after the load reaches a value about $260 \mathrm{kN}$, it is observed that this model shall produce increasing displacement with almost a constant load, i.e., the curve after it reaches a load of $260 \mathrm{kN}$, starts to flatten or level off. This behavior is not observed for models C2-1 and C3-1 confined with two and three layers of CFRP respectively. For FE model confined with two layers of CFRP (C2-1), the load-displacement behavior tends to be a smooth curve with no distinguishable yield value. Obviously, this model that is confined with two layers experience less displacement compared to the model confined with one layer under the same stress. Finally, the model C3-1 that is confined with three layers, behaved similarly to the model confined with two layers; in that it behaves like a smooth curve with no distinguishable yield value. Also obviously, the displacement resulted from confining the model with three layers (C3-1) is the least displacement experienced compared to the displacement underwent by the other two models (C1-1 and C2-1). In other words, the displacement resulted from three-layer confinement is the least compared to the models that are confined with one and two layer of CFRP under the same load.

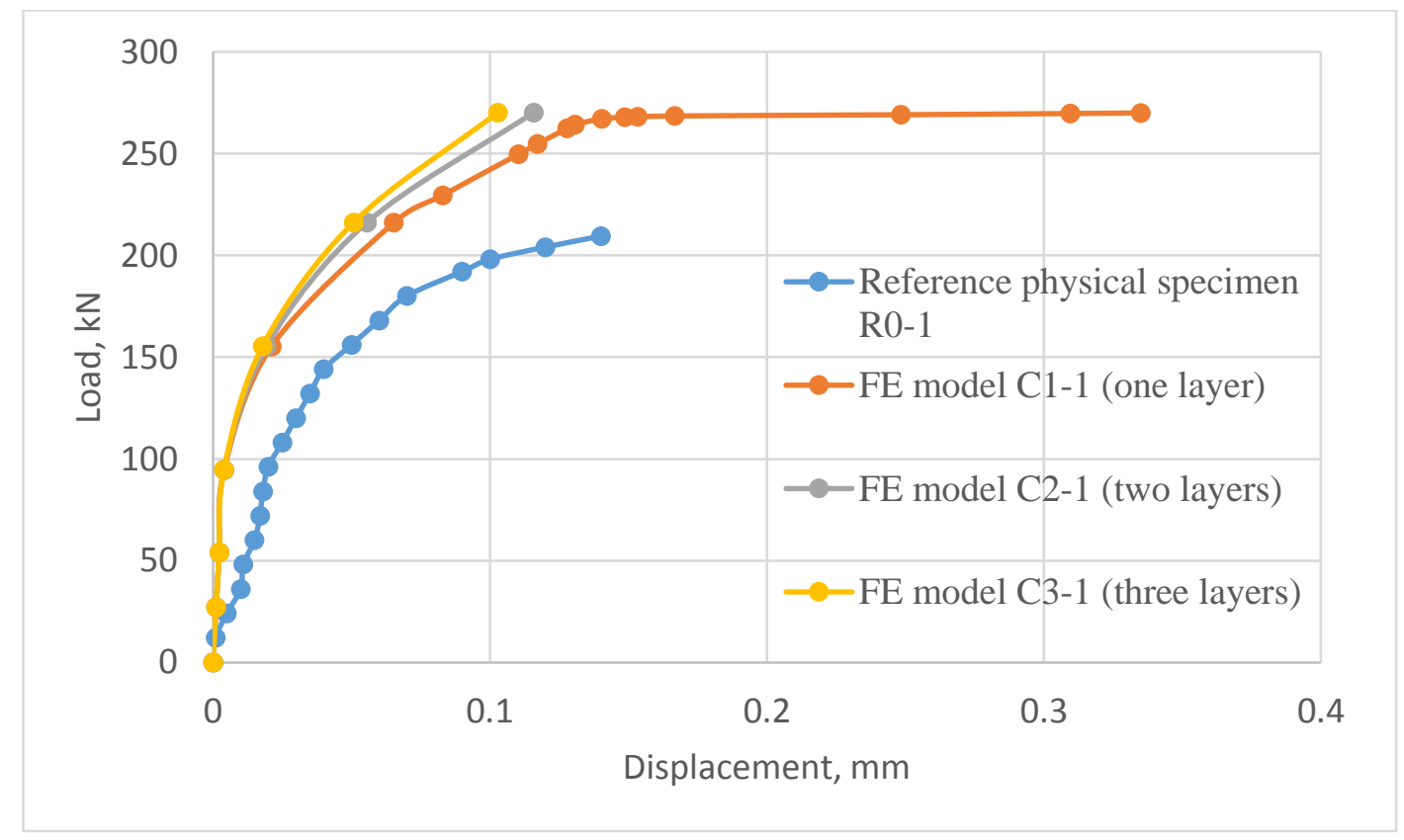

Figure 13. Compressive stress-strain curve for model C1-1 confined by multi-layers of CFRP. 
An important conclusion is reached; which is that for the same stress, and with increased wrap thickness, i.e., increased number of CFRP wraps, the compression member behaves more rigid with each layer added for confinement. In other words, the more layers of CFRP added to the member, the more rigid it becomes, also, the less layers of CFRP added the less rigid it becomes.

\section{CONCLUSIONS}

- Strengthening square compression members by providing external confinement by one layer of CFRP wraps produced conveniently good results, where in terms of load carrying capacity, an enhancement was up to 56\%. This high increment in load carrying capacity is attributed to the mode of failure which was premature failure.

- Failure of confined square or rectangular compression members happens at zones of stress concertation, i.e. at corners or sharp edges of the cross section.

- For the case if the compression members were cast with low strength concrete mixture, or if the wraps possessed high strength, a type of failure may occur in compression confined members which is premature failure. Premature failure means that the member has reached its ultimate strain or strength capacity and it fails by crushing of the concrete, all of this while the wraps were not damaged yet.

- Adopting a Concrete Damaged Plasticity Model (CDPM) for modeling concrete compression members proved satisfactory and convenient results when compared with experimental results.

- The general trend of behavior for the load-displacement curves of the experimental and the FE is similar. The FE curve slightly overlie the experimental curve, i.e. FE analysis provides higher strength than the experimental one.

- When confining square compression members with more than one layer of CFRP wraps, e.g., one, two, and three layers, it is observed that the compression members tend to be more rigid as the number of wraps increases. The same applies to confined circularized square members, where it is noticed that increasing the number of CFRP confining layers causes the compression members to be more brittle.

- Using CDPM in Abaqus CAE produced conveniently good results. When the numerical results (obtained from CDPM) were validated with the experimental results, the numerical results showed a very good agreement with the experimental results.

- Defining CFRP wraps in Abaqus as lamina elastic material produced very good results when validated with the experimental results.

\section{REFERENCES}

- Abdulhameed, A. A. \& Said, I. A., 2019. Behaviour of Segmental Concrete Beams Reinforced by Pultruded CFRP Plates: An Experimental Study. Journal of Engineering, Volume 25.

- ACI Committee 318, 2014. Building Code Requirements for Structural Concrete. ACI 318.

- ACI 440.2R-08. (2008). Guide for the Design and Construction of Externally Bonded FRP Systems for Strengthening Concrete Structures. American Concrete Institute (ACI) Committee 440.

- Al-Khafaji, H. (2016). Experimental Investigation of CFRP Wrapped Square Non-Ductile Reinforced Concrete Columns. Portland state university pdx scholar. doi:10.15760/etd.3330. 
- Al-Quraishi, H., Ghanim, G. \& Asaad, Z., 2017. Compressive Strength of Bottle-Shaped Compression Fields of Fiber Reinforced Concrete Members. Journal of Engineering, Volume 23.

- Benzaid, R. \& Mesbah, H.-A., 2013. Circular and Square Concrete Columns Externally Confined by CFRP Composite: Experimental Investigation and Effective Strength Models. Fiber Reinforced Polymers - The Technology Applied for Concrete Repair. Available at: http://dx.doi.org/10.5772/51589.

- Campione, G., Miraglia, N. \& Papia, M., 2004. Strength and strain enhancements of concrete columns confined with FRP sheets. Structural Engineering and Mechanics, 18(6), pp.769-790. Available at: http://dx.doi.org/10.12989/sem.2004.18.6.769.

- Carreira, D. J. \& Chu, K.-H., 1985. Stress-Strain Relationship for Plain Concrete in Compression. ACI Journal Proceedings, 82(6). Available at: http://dx.doi.org/10.14359/10390.

- Carreira, D. J. \& Chu, K.-H., 1986. Stress-Strain Relationship for Reinforced Concrete in Tension. ACI Journal Proceedings, 83(1). Available at: http://dx.doi.org/10.14359/1756.

- V. Chaudhari, S. \& A. Chakrabarti, M., 2012. Modeling of Concrete for Nonlinear Analysis using Finite Element Code ABAQUS. International Journal of Computer Applications, 44(7), pp.14-18. Available at: http://dx.doi.org/10.5120/6274-8437.

- Dere, Y., 2017. Nonlinear FE Modeling of Reinforced Concrete. International Journal of Structural and Civil Engineering Research, pp.71-74. Available at: http://dx.doi.org/10.18178/ijscer.6.1.71-74.

- Genikomsou, A. (2015). Nonlinear Finite Element Analysis of Punching Shear of Reinforced Concrete Slab-Column Connections. University of Waterloo, 94-109.

- Khan, A.-u.-R. \& Fareed, S., 2012. Confinement of Short Concrete Columns with CFRP Wraps Subjected to Concentric and Eccentric Loading. Taylor \& Francis Group.

- Labibzadeh, M., and Hamidi, R. (September 2016). Assessment of Size Effect in Concrete Damage Plasticity Model. Conference: The First Conference on Practice Researches in Structural Engineering and Construction Management.

- Lin, G. \& Teng, J. G., 2013. FRP-CONFINED CONCRETE IN SQUARE COLUMNS: AN ADVANCED STRESS-STRAIN MODEL BASED ON A NEW APPROACH. Melbourne, Australia

- Nilson, A. H., Darwin, D. \& Dolan, C. W., 2010. Design of concrete structures. 14th ed. New York: McGraw-Hill Companies, Inc.

- Ozbakkaloglu, T., Lim, J.C. \& Vincent, T., 2013. FRP-confined concrete in circular sections: Review and assessment of stress-strain models. Engineering Structures, 49, pp.1068-1088. Available at: http://dx.doi.org/10.1016/j.engstruct.2012.06.010.

- Tipnis, O. P., 2015. NUMERICAL AND ANALYTICAL MODELING OF CONCRETE CONFINED WITH FRP WRAPS. The Pennsylvania State University.

- Wahalathantri, B. L., Thambiratnam, D. P., Chan, T. H. \& Fawzia, S., 2011. A material model for flexural crack simulation in reinforced concrete elements using ABAQUS. Brisbane, Australia, Proceedings of the First International Conference, Queensland University of Technology, Queensland.

- Xiao, Q.G. et al., 2011. Three-Dimensional Finite Element Model for FRP-Confined Circular Concrete Cylinders under Axial Compression. Advances in FRP Composites in Civil Engineering, pp.654-657. Available at: http://dx.doi.org/10.1007/978-3-642-17487$\underline{2} 144$. 